Revista de la red interuniversitaria de estudios sobre las literaturas rioplatenses contemporáneas en Francia

\title{
Vacilante vida escrita del novelista argentino. Diario de escritor editado por el autor, entre presentes y comienzos
}

Vie écrite hésitante du romancier argentin. Les journaux d'écrivains publiés par leurs auteurs, entre présents et commencements Vacillating written life of the Argentine novelist. Writer's diary edited by the author, between present and beginnings.

\section{Juan Pablo Luppi}

\section{(2) OpenEdition}

\section{Journals}

Electronic version

URL: http://journals.openedition.org/lirico/8650

DOI: $10.4000 /$ lirico.8650

ISSN: 2262-8339

\section{Publisher}

Réseau interuniversitaire d'étude des littératures contemporaines du Río de la Plata

Electronic reference

Juan Pablo Luppi, « Vacilante vida escrita del novelista argentino. Diario de escritor editado por el autor, entre presentes y comienzos », Cuadernos LIRICO [En línea], 20 | 2019, Publicado el 10 julio 2019, consultado el 02 junio 2020. URL : http://journals.openedition.org/lirico/8650 ; DOI : https://doi.org/ 10.4000/lirico.8650

This text was automatically generated on 2 June 2020 . 


\section{Vacilante vida escrita del novelista argentino. Diario de escritor editado por el autor, entre presentes y comienzos}

Vie écrite hésitante du romancier argentin. Les journaux d'écrivains publiés par leurs auteurs, entre présents et commencements

Vacillating written life of the Argentine novelist. Writer's diary edited by the author, between present and beginnings.

Juan Pablo Luppi

La novela que quiero escribir es más bien por el momento un deseo impreciso

(6 de abril de 1976)

En este diario hay una intriga: qué habrá de suceder al fin y al cabo con esa seguridad que, en el fondo, siempre tuve sobre mi futuro como escritor.

(21 de diciembre de 1977) Ricardo Piglia, Los diarios de Emilio Renzi. Un día en la vida $(24,59)$

\section{Los yo oscilantes}

A medio siglo de la transición del estructuralismo a su post, sabemos que lo autobiográfico, mejor que un género reglamentado, sería un espacio irregular que atraviesa toda escritura y lectura. Priorizando la naturaleza sustitutiva del lenguaje, en 1979 De Man desarrolló implicancias productivas de la autobiografía como "una figura de lectura y de entendimiento que se da, hasta cierto punto, en todo texto" (1991: 114). 
El problema pasa menos por la identidad que por la alteración de subjetividades en la interfase lectura/escritura y la multiplicidad del pronombre axial: el yo pivotea la variación pronominal y abre grietas en la presunta equivalencia con el autor, desfigurado en el texto que lo configura. Como analizó Benveniste (1971: 180, 184, 186-187), el yo y el tú se definen por relación mutua, son reversibles, complementarios, y la tercera persona extrae su valor de la enunciación de un yo en el marco de realidad del discurso, como lengua asumida por el hablante en condición de intersubjetividad. Cada idioma intensifica a su modo los lugares del sujeto en la lengua. Tres años después de su publicación francesa en 1975 (en sincronía con Le pacte autobiographique de Lejeune, al que torna obsoleto pese a su larga influencia en el campo académico), la traducción española de Roland Barthes par Roland Barthes se resigna al genérico "Pronombres" para el intertítulo lacónico que indica la pluralidad de la primera persona singular con un sintagma frecuente en francés: "Moi, je". Con la programática evitación de "la vieja pareja [...] subjetividad/objetividad", Barthes expande la heterogeneidad gramatical para propiciar una subjetividad "desconstruida, desunida, deportada, sin anclaje": "todo está en juego precisamente aquí, estoy encerrado para siempre en la lid pronominal: "yo" moviliza el imaginario, "usted" y "él", la paranoia" (1978: 184). Más que un yo referido a un sujeto biográfico, en el dinámico campo de batalla pronominal emergen diversos yo barridos por la escritura de vida que desplazan infinitamente la identidad del supuesto demiurgo que firma el libro. Singulares apropiaciones de esa deconstrucción del pacto referencial reverberan en ficciones autobiográficas de dos novelistas argentinos, diversamente consagrados en el cambio de milenio, que editan sus notas fechadas desde los comienzos, los años de preparación de la (primera) novela, sincrónicos con la recepción de Barthes; confrontaremos los diarios de escritor publicados a mediados de la segunda década del XXI por Ricardo Piglia y Rodolfo Rabanal, para priorizar un análisis del imaginario del novelista vacilante en el segundo, menos triunfal que el del primero.

2 Desarmando la fijeza clasificatoria de Lejeune (constreñida a la equivalencia entre autor-narrador-personaje) los fragmentos que arman R.B. por R.B. se tensan en torno al emplazamiento del yo en el imaginario. Antes del texto pautado por intertítulos, la preliminar treintena de páginas en itálicas inserta fotografías domésticas del autor, como si empezara deshaciendo toda semejanza desde la evidencia visual del álbum familiar; ante la reacción del yo por no parecerse a los sujetos que allí vemos, una emisión anónima le responde con raya de diálogo, simulando la voz paranoica de lo real o de los otros distintos que salen del yo, como él o usted:

¿Qué es ese "usted" al que usted se parecería o no? [...] Usted es el único que no podrá nunca verse más que en imagen, usted nunca ve sus propios ojos a no ser que estén embrutecidos por la mirada que posan en el espejo o en el objetivo de la cámara [...]: aun y sobre todo respecto a su propio cuerpo, usted está condenado al imaginario (40).

3 Al desplegar fisuras probables de la imposibilidad de verse a sí mismo desde afuera, Barthes moviliza la pugna pronominal para narrar los dobleces del yo. Como proponía Crítica y verdad en 1966, el sujeto no es una plenitud individual que pueda evacuarse en algún género discursivo, sino "un vacío en torno del cual el escritor teje una palabra infinitamente transformada": "El lenguaje no es el predicado de un sujeto, inexpresable, o que aquél serviría para expresar: es el sujeto" (1972: 73). En Sade, Fourier, Loyola (1971), observa Catelli, Barthes circunscribe el imaginario por paráfrasis de Lacan, como efecto sospechoso del "desconocimiento que el sujeto tiene de sí mismo 
en el momento en que se decide a asumir y actuar como su yo"; en ese efecto del desconocimiento, la dimensión imaginaria dinamiza el autoconocimiento y puede servir como herramienta para comprender transformaciones históricas (2007: 10; itálicas en original). A la vez que evita la demanda de identidad oscilando entre la segunda y la tercera personas referidas al yo que escribe (desde el título en tercera, borrando la firma autoral por redundante), R.B. por R.B. practica la fragmentación y dilación como alternativas a la fijeza del pacto: "Tiene la manía de hacer "introducciones", "esbozos", "elementos" posponiendo para más tarde el "verdadero" libro. [...]. Estos proyectos viven, nunca los abandona; suspendidos, pueden cobrar vida en cualquier momento". Las huellas de esa obsesión se realizan parcialmente a través de temas, planes, papeleo suscitado por la compulsión del programa que emplaza al yo en el usted: "usted alarga el tiempo que le falta con la inscripción misma de esa falta". La fuerza del libro estaría en la posibilidad utópica de convertir la falta en escritura: "Invirtamos ahora todo esto: estas maniobras dilatorias, estos esconces del proyecto son tal vez la escritura misma" (1978: 188-190).

4 Condenado al imaginario y a la dificultad de manejar el yo, Barthes pasa por el tamiz pronominal la intuición de que escribir es tomarse por otro. Como sintetizaba Piglia en la "Nota" preliminar al libro Yo, antología de fragmentos autobiográficos de la literatura argentina desde el XIX al presente de 1968, "el YO es, de todos los signos del lenguaje, el más difícil de manejar", y "el escritor ha adquirido la costumbre de hablar de sí mismo como si se tratara de otro". Aunque en una autobiografía "el YO es todo el espectáculo [...], objeto y sujeto de la narración", "por el solo hecho de escribir, el autor prueba que no se habla solamente a sí mismo". La lógica que estructura los hechos no es la de la sinceridad sino la del lenguaje, que permite entrever el espesor de una época y el nivel de conciencia que el hablante tiene de sí y del mundo (5-6; mayúsculas en original). Desplazando la demanda de veracidad, la lógica del lenguaje suscita la hibridez entre autobiografía y ficción, particularmente productiva en la literatura argentina desde Facundo (1845) de Sarmiento, donde lo novelesco mezclado con lo histórico y lo (auto)biográfico reformula conexiones entre yo-otros, verdad-ficción, pasado-presente, oralidad-notación-impresión. Como observa Piglia, esta "especie literaria" tiene en Argentina una tradición fértil, que dispone una serie abierta de escenas narrativas cuyo protagonista es un yo que, al escribir, interviene sobre las formas de vida individual y colectiva, un sujeto vinculado a oficios letrados con tensiones específicas entre tiempo y dinero, contactos del campo cultural, estrategias de circulación y existencia social de la obra, construcción de una imagen de autor a partir de cierta formación literaria. En otras intervenciones Piglia ha sistematizado las conexiones de lo autobiográfico con la crítica y la ficción: "La crítica es una forma postfreudiana de la autobiografía", dice en una entrevista de 1984; en tanto experiencia intensa con la pasión, tiene la misma estructura de la vida: "Alguien escribe su vida cuando cree escribir sus lecturas" (1993: 16, 19, 24). El efecto de credibilidad del relato de una vida se juega a través de los procedimientos retóricos de la ficción; más que la verdad o la referencialidad, importa la construcción narrativa, la cualidad autorreflexiva significante (Arfuch 2002: 59-60). Importan sobre todo las estrategias de lectura, como detectan Domínguez y Rodríguez Pérsico al revaluar en 1984 la autobiografía de Victoria Ocampo, matizando el contrato de Lejeune como "un código mínimo" que "contiene las desviaciones", lo que les permite apreciar el problema del "modo de lectura" común a autobiografías, memorias, testimonios, discursos situados "en el borde impreciso entre lo literario y lo extra literario". En lo vivido pasado a 
escrito, entre ése que fue y el que es ahora se instala la narración, transformando al yo en narrador y objeto narrado: "Entre ambos y apoderándose de ellos está el lenguaje" (23-24).

5 Como leyó Barthes en el desplazamiento entre escritura y vida en Proust, la narración (auto)biográfica no es la exposición ordenada de una vida sino el relato, a menudo turbulento, de un deseo de escribir (Dosse 2007: 66). En las notas del curso universitario de 1980 sobre ese deseo volcado a la preparación de la novela, Barthes repasa su propio vaivén teórico entre la muerte del autor -su indiferencia como principio ético de la escritura contemporánea, según Foucault citando a Beckett en 1968- y el giro subjetivo -que desde mediados de los 80 provoca una redefinición del autor y la recuperación de su lugar en el espacio público (cf. Premat 2006)-. Entreverando autobiografía y crítica, Barthes anota que en el momento de El placer del texto (1973) se produjo una "conmoción del superyó teórico", con el retorno de "un gusto por [...] la nebulosa biográfica" y el gesto de "volver a poner en la producción intelectual un poco de afectividad "psicológica": dejar un poco hablar al "Yo"”. La inutilidad de distinguir entre narrador, autor y personaje en la novela de Proust permite postular un espacio diverso de la biografía, al que denomina "la escritura de vida, la vida escrita (en el sentido fuerte, transformador de la palabra "escritura")". Más que el autor, en esa biografemática interesan "los roles barridos por la escritura de vida [...], los yo que escriben sucesivamente" y conforman "la complejidad de la red de enunciación, es decir, de los empleos y los roles del Yo". Con resabios estructuralistas establece una tipología de los yo que suceden en la escritura: persona (el sujeto civil, que vive afuera de la escritura), scriptor (el escritor como imagen social, aquel del que se habla), auctor (el padre de la obra, garante que asume su responsabilidad), scribens (el yo que está en la práctica de escribir, que vive cotidianamente la escritura) (2005: 276-279; itálicas en original).

6 Trazos de esos yo conviven en los desplazamientos temporales y textuales que practican novelistas argentinos formados en los años de la muerte del autor, como Piglia y Rabanal, que editan sus diarios de formación cuando el giro subjetivo lleva un cuarto de siglo intensificándose. Con menos visibilidad editorial pero similar imaginación fronteriza entre autobiografía y ficción, sin asignarse un alter ego escritor ni prometer la publicación de míticos cuadernos personales, La vida escrita de Rabanal propone en 2014 otra versión del libro que al año siguiente lanza Piglia como primer volumen de Los diarios de Emilio Renzi. Especies de novelas hechas por montaje de diarios y anotaciones, cuya polifonía está en las charlas y (auto)lecturas del yo y su dialogismo en los sucesivos yo que escriben, ambos libros realizan la utopía de narrar la historia de una primera persona que solo existe en el presente de enunciación y desde allí evoca al que ha sido, atravesado por la cíclica crisis pública en que vive y escribe, cuya materialización los vuelve originarios en cuanto contemporáneos. Como detecta Molloy en la figura repetida a comienzos del siglo XIX de un yo en crisis que escribe en un vacío interlocutorio, la escritura autobiográfica en Hispanoamérica se caracteriza por la vacilación, las tensiones de conexión entre persona pública y privada, sujeto y patria, pasado y presente: "La evocación del pasado está condicionada por la autofiguración del sujeto en el presente: la imagen que el autobiógrafo tiene de sí, la que desea proyectar o la que el público exige" (1996: 11, 14-15). El despliegue del futuro hace de la oscilación hispanoamericana un problema fundacional, original en el sentido de Agamben: "el origen no se sitúa solamente en un pasado cronológico: es contemporáneo al devenir histórico y no cesa de funcionar en este” (2010: 79-80). Ese 
origen renovable ocuparía la primera novela de Rabanal para el autor de La vida escrita, como veremos.

Ordenado cronológicamente desde los Años de formación (de 1957 a 1967) hasta 1982 más una sección de entradas posteriores sin fechar, Los diarios de Emilio Renzi (tres volúmenes publicados entre 2015 y 2017) relativiza la vacilación que caracteriza la escritura autobiográfica hispanoamericana según Molloy, al consolidar la autofiguración presente del autor consagrado y ubicar desde los comienzos la profecía realizada de un destino de escritor. Menos (o de otro modo) barthesiano que el narrador dubitativo y versátil de Rabanal, el categórico narrador de Piglia muestra obstinaciones similares a las que analizaremos en La vida escrita, como las fuerzas ciegas que impulsan el estilo y el destino, el yo como otro, la notación fragmentaria como preparación de la novela, las lecturas propias y ajenas de escrituras propias y ajenas. Valgan dos citas del primer volumen de Piglia, los años de formación también priorizados, de otro modo, por Rabanal. El último día de 1965, Renzi anota que desde el comienzo (1958-1959) "yo decidí mi destino ciegamente", y resume la experiencia (programa realizado cincuenta años después) de desdoblamiento del yo y generación de un relato por extracción de la relectura íntima: "Releer mis "cuadernos" es una experiencia novedosa, quizá se puede extraer, de esa lectura, un relato. Todo el tiempo me asombro, como si yo fuera otro (y es lo que soy)". Si, como veremos, la escritura de vida de Rabanal ubica su primera novela en una temporalidad múltiple (planeada, procesual, próxima y, a la vez, realizada, publicada, reseñada), la novela atraviesa la formación de Renzi con tensión de futuro, surgiendo de la notación manuscrita, de los rincones del proyecto, en una pugna con las formas breves que no parece preocupar a Rabanal (ni a Barthes): "Hay un riesgo pero también una gracia que me lleva de las notas fragmentarias de la novela a la busca de un tono en este cuaderno", edita Piglia el deseo de Renzi fechado el 2 de enero de 1967: "Busco una prosa de media distancia que me permita salir de las formas breves" (2015: 212-213, 282). Menos inmediata que la de Rabanal, la primera novela de Piglia no será la que anotaba en sus años de formación - "novela imaginada" con título tomado de Faulkner, Campo de batalla, entre reflexiones sobre Capote y non fiction, "una novela "disfrazada" de ficción verdadera" (283-284) que devendría en 1998 Plata quemada - sino Respiración artificial que, una década después de esa momentáneamente fallida preparación de la novela, corona la larga temporada dedicada a convertirse en escritor.

El tercer tomo de Los diarios de Emilio Renzi (Un día en la vida, publicado póstumo en 2017) intensifica las reflexiones sobre "este diario" para sistematizar la resolución que Piglia ha dado a esa tensión entre las formas breves de los días anotados y el estilo fragmentario entre crítica y ficción que convirtió en prosa de novela. Desde el umbral (el primer texto, "Sesenta segundos en la realidad", antes del diario fechado) programa su unidad "siempre retrospectiva" y el afán por editarlo alterando la causalidad cronológica, problematizada en el hiato entre la intimidad de lectura/escritura y la publicación/lectura ajena: al emprender "la tarea de leerlos e intentar pasarlos a máquina [...], había desertado de la espantosa sucesión cronológica”, pero la necesidad de dar a leer lleva a "publicar [...] sus notas personales siguiendo el orden de los días". A ese orden se comprime la última de las tres partes del tercer tomo, "Días sin fecha" que agrupa notas nombradas por subsiguientes días de semana (lunes, jueves, viernes) sin mención de meses ni años: la espantosa sucesión diarística de los dos tomos y medio anteriores, además de estar atravesada por textos fuera de diario (en general nouvelles piglianas en torno a la escritura de vida del lector-escritor), resulta al cabo destronada 
en los once textos que, en la tercera parte del tercer volumen de Los diarios, liberan a los días de fecha, al convertir notas del último lustro de vida en esas formas breves con títulos autónomos, como las que Piglia apreciaba en Kafka. La tercera parte difumina el orden historicista del libro (como diario en la primera parte, "Los años de la peste", de enero de 1976 a septiembre de 1982) y menciona desplazado, anotado hacia el final y frustrado por todo lo previo, el deseo de "editar este diario en secuencias que sigan las series" (encuentros con amigos, visitas a la madre) para "alterar la causalidad cronológica". Los diarios de Emilio Renzi lograría alterar la causalidad (porque "lo que estaba escrito en su diario era la vida misma, con sus caóticas repeticiones") mejor que la sucesión cronológica considerada espantosa en el inicio del último tomo. La profecía autorrealizada de convertirse en escritor se materializa en el libro con la decisión de interrumpir en 1982 el diario sucesivo abierto en 1957: en 1982 se ha completado el destino allí anunciado, cuando Respiración artificial ha sido escrita (entre marzo del 76 y febrero del 80), titulada (el 5 de junio del 80), publicada (en noviembre del 80) y celebrada más allá del círculo de amigos ("el libro está en la lista de best sellers de Clarín", "se han vendido siete mil quinientos ejemplares" en menos de un año, José Bianco elogia la novela, "se la leyó a Borges"). Al cierre de la parte diarística sigue la sistematización de "Los finales", que resuelve la intriga que Rabanal dejará suspendida, la que Renzi había planteado en diciembre de 1977 (segundo epígrafe de este trabajo): "había pensado que esa temporada de su vida había terminado y que los veinticinco años dedicados a convertirse en escritor estaban concluidos" (2017: 10, 22, 109-113, 141, $148,160,184,271)$.

\section{El novelista tentativo}

9 A diferencia de Renzi, Rabanal no escribe su vida como proceso autocumplido de convertirse en escritor; desdeñando la pulsión teleológica, edita la evitación de ese destino manifiesto. Con sus propias obstinaciones, dispone un espacio de despliegue del sujeto que vive escribiendo, que al escribir se desfigura y deja en la escritura el vacío que descubre la máscara de la persona civil. Esa impostura sería el espacio autobiográfico, el lugar donde un yo proclama que fue aquello que hoy escribe, y convierte en literatura el fracaso de tal proclama:

[...] la presuposición de semejanza (entre el yo del pasado y el yo del presente, entre quien dice yo y quien escribe yo [...]) es un sueño o una aspiración de raíz romántica. Pero, al convertirse en literatura, la búsqueda de la semejanza, condenada teóricamente al fracaso, alcanza, no obstante, su culminación estética (Catelli 1991: 12; itálicas en original).

10 Formulada en la oscilación entre necesidad e imposibilidad del lenguaje de remitir a un yo, la escritura de vida de Rabanal explora otros agenciamientos entre autor, narrador, personaje, lector, y extrae del fracaso de la semejanza una extraña potencia novelesca, cuya intriga es más ambigua y espesa que la conclusión exitosa de Renzi tras el cuarto de siglo dedicado a convertirse en escritor.

11 La vida escrita narra el imaginario como lugar inestable de quien vive escribiendo, y persigue los orígenes dilatados del novelista que el yo ha intentado ser, en un montaje anacrónico -como Proust leído por Didi-Huberman (2008: 62) - de vivencias y lecturas. El artificio de autoedición en 2014 de la vida registrada entre 1972 y las proximidades del 90 dispone una forma novelesca, atrapante en el suspenso de la notación en presente, que multiplica la intriga encarada por Barthes entre la muerte del autor a 
fines de los 60 y el giro subjetivo que le siguió: ¿quién es ese fantasma que aparecedesaparece cada vez que se escribe yo? Quebrando el orden cronológico que espanta a Renzi sin evitarlo, disponiendo el espacio impreso como convergencia de fragmentos que cruzan intrigas abiertas (de modo menos programático, menos policial que Piglia), lo autobiográfico encuentra la novela para jugar con la presunción mimética y producir un sentimiento de verdad a partir del imaginario del sujeto-objeto de escritura. Mejor que el relato de una vida, la lengua autosuficiente hundida en la mitología secreta del autor (como anota Rabanal leyendo a Barthes en 1975) formula un deseo de escribir, editado como anotación heterocrónica con el suspenso de una obra irresuelta por la tentativa de vivir escribiendo y hacer de la vida escritura. Ese deseo, ese suspenso vital sería la novela. Como en R.B. por R.B., en La vida escrita todo puede "ser considerado como algo dicho por un personaje de novela -o más bien por varios-"; también el montaje de Rabanal escalona "varias máscaras (personas)" encargadas del imaginario, "materia fatal de la novela": la sustancia del libro sería "enteramente novelesca", y el ensayo deberá confesar "ser casi una novela" (Barthes 1978: 131; itálicas en original).

Bajo máscara de totalidad la novela es un casi, bordeado por autobiografía y ensayo, tentativo y desplazado: la novela es preparación, propensión hacia sí misma. Como la notación y el haiku en La preparación de la novela, La vida escrita extiende formas breves personales en una hechura mayor que indaga el supuesto género consagrado de la modernidad. Texto híbrido que cose paratextos, dispositivo proteico que alberga en potencia todos los géneros sin serlo, la novela se constituye en los bordes materiales del espacio editorial, desde el periódico (en la sección del folletín en la prensa del siglo XIX) y desde el diario íntimo, la anotación personal, la correspondencia privada, los gajos manuscritos detrás de lo impreso. Hilvanando notas rescatadas de esos rincones, La vida escrita acciona la "propensión a la novela" que Rabanal veía como su marca de estilo a fines de los 90, al prologar un libro de relatos escritos durante "un período de alrededor de veinte años", que con "Manuel Saurat, un diario íntimo" (1999: 141-149) incluye el diseño germinal del personaje autoral, que "cobraría forma" entre En otra parte (1980), El factor sentimental (1990) y, ya con el nombre de Saurat, oscilando entre tercera y primera personas, La vida brillante (1993). Las siete entradas evanescentes de ese relato fechado en 1978 conforman un incipiente diario del yo como otro a la manera de Piglia con Renzi, aunque con menos armonía entre el yo y su otro, según el prólogo autoral: allí empezó Saurat "a insinuárseme de manera persistente y engorrosa, a veces como alter ego novelesco y otras como un entrometido confrontado a mis propias cavilaciones literarias" (1999: 5, 7-8). Quince años después de este balance sentimental, Rabanal desplazará a Saurat para devenir personaje autoral él mismo (como otro, el ajeno), en la edición de las cavilaciones anotadas durante otro período de alrededor de veinte años (en parte superpuesto al fechado en 1999), titulada con apropiación de Barthes cuando ve en Proust un espacio diverso de la biografía (como ya citamos): "la vida escrita (en el sentido fuerte, transformador de la palabra "escritura")".

Con el diseño envolvente de un folletín anacrónico en la era digital de la intimidad exhibida, el montaje de La vida escrita problematiza la imagen del autor proyectada en relación con el público contemporáneo y futuro, la de novelista consagrado. Aventura mayor de quien vive escribiendo, la novela emerge editando secuencias dispersas del epitexto privado, ese umbral situado "al menos al principio, en el exterior del libro", que entre autor y público interpone un primer destinatario que es el mismo autor, de cuya interlocución hace testigo al público (Genette 2001: 10,320). En los bordes entre la visibilidad social de la novela y la zona secreta del paratexto - "mensajes que se dirige 
el autor a sí mismo, en su diario o en otra parte", "íntimo por el hecho de su autodestinación" (14; itálicas en original) - Rabanal arma su vida escrita como reunión de fragmentos reflexivos y narrativos que, según la nota prologal, "siempre refieren hechos, acciones, sospechas, sueños y proyectos que "sucedieron de verdad"' (Rabanal 2014: 9). Por esa zona ambigua avanza la narración de la vida del que escribe y de los yo que suceden en su escritura, generando intriga en torno al abandono de la persona (el individuo que vivía sin escribir) para convertirse en scribens (el que vive cotidianamente la escritura) y, con la publicación de su primera novela (El apartado en 1975), comenzar a ser auctor (asumir la responsabilidad de poner una obra en el mundo) hasta consolidar una imagen social como scriptor (serenamente afianzada para 2014, cuando hace años que El apartado devino novela de culto). El espacio híbrido desplegado por el yo irresoluto se condensa en la pregunta emergente entre anotaciones fechadas el año clave de los comienzos (1975, cuando aparecen los libros dispares de Lejeune y Barthes), como cambiando de tema aunque encarando el único y rizomático asunto de esta novela probable: "Por otra parte, ¿no es este seguimiento de notas privadas (personales) e íntimas una variante ficcional de mi propia vida?” (68-69).

Como en Los diarios de Emilio Renzi pero evitando el orden cronológico que sigue la autoedición del epitexto privado de Piglia, la anotación desoculta los orígenes del novelista que Rabanal ha intentado ser; la tentativa sigue abierta porque el anacronismo pauta el trabajo del escritor. Al comienzo del libro, una nota fechada en 1988 (cuando Rabanal publica su quinta novela y su primer libro de cuentos) vale como presentación del protagonista, mientras lee "sobre informática" y constata la proximidad de "un mundo de desarrollos inesperados": "el novelista que intento ser se me antoja un hombre "antiguo", un renacentista sin Renacimiento" (16). Setenta páginas después narra el comienzo del intento, fechado en abril de 1974: "Empecé a escribir en Semana Santa a un ritmo estimulante. Novela, aún sin título. Todo empieza con un planteo interrogativo porque, en realidad, no sé nada, no sé todavía qué es y de qué trata". Todo empieza con una escritura tentativa, señalada con adjetivación barthesiana ("texto fantasmático en una ciudad fantasma"), cuyo arranque ha desdoblado al autor "como si alguien metido en mí escribiera por mí" (81). Mezcladas a la historia de ese texto que será El apartado - publicado por Enrique Pezzoni en Sudamericana en septiembre del 75 - se despliegan anécdotas del campo cultural y charlas literarias, contiguas a ideas y dilemas para seguir escribiendo, planes de personajes y relatos, comentarios sobre libros que va leyendo, fragmentos de películas y músicas, en fin, la historia secreta del novelista que el yo ha intentado ser. El desdoblamiento iniciado con la escritura de la primera novela, la extrañeza fantasmática que ese trabajo transpone a la ciudad y los días, continúa en las notas del final del período abarcado; un fragmento fechado en octubre de 1988 comienza: "Días más bien extraños. Como si yo fuera otro. El ajeno" (44).

La autobiografía desplazada en notas heterocrónicas, que saltan por diversos presentes durante dos décadas, problematiza de otro modo que Piglia el hiato entre intimidad y publicación abierto cuando se da a leer: arranca con lecturas mías, lo que lee cotidianamente, y muy avanzada hace lugar a lecturas de mí, lo que alguna reseña ha dicho sobre $E l$ apartado. Antes de ubicarse en el presente de la novela iniciática (1979: 75, 78 y 74, en ese desorden cronológico), las primeras seis páginas (con entradas fechadas entre julio de 1987 y julio del 88) están recorridas por notas de filosofía, literatura, cine: comentarios del Diario de Wittgenstein, la decisión de lectura íntima de hacer a un lado a Shepard para encarar a Bernhard, la semblanza de dos amigos poetas 
(Francisco Madariaga y Edgar Bayley) que en un encuentro universitario se comportan como Hamm y Clov en Fin de partida de Beckett, una charla amical sobre Bajo el volcán de Lowry, la "[f]uerte incitación literaria" al ver Las alas del deseo de Wenders, una luz de ocaso comparada con el color utilizado por Hitchcock en La ventana indiscreta (11-17). Al pasar a notas fechadas en los 70 se corta con esa biblio/videoteca personal, en un desplazamiento hacia la sociabilidad cultural porteña que a su vez incluye charlas con escritores, como la de 1979 con Piglia, en la que descubren que ambos están leyendo la misma novela de Bernhard, "apenas conocido entre nosotros" (18).

A mediados de los 70 (poco antes de que Piglia empiece a escribir lo que será Respiración artificial) aparece la propia novela, y la autoconvicción del yo intentando ser novelista con humorada martirizante: "Escribí mi novela -que ahora se llama definitivamente $\mathrm{El}$ apartado- el año pasado, a la edad de Cristo". Cuando reaparece la lectura apropiadora, en esa misma página fechada en marzo del 75 , emerge Barthes en diálogo con el entusiasmo vital del yo por haber escrito una novela: "Me gusta esta frase de Roland Barthes: "Lengua y estilo son fuerzas ciegas". Sí, yo no sé a qué fuerza obedezco cuando escribo" (22). La felicidad de aquel trabajo de escribir "durante horas y horas, todos los días, hasta el agotamiento", resulta un año después mitigada por el temor de "que ese embale me haya abandonado"; otra cita de Barthes, sobre el estilo como "lenguaje autárquico que se hunde en la mitología personal y secreta del autor", es seguida por dos oraciones cuyo punto y aparte (lo indico con barra) tensiona la autoconfianza de quien ha producido una primera novela por entonces inédita: "Creo que es verdad. / Espero que sea verdad" (23). Fuerza ciega, embale inconstante entre creencia y esperanza, lenguaje hundido en la mitología secreta del autor serían merodeos de lo que Barthes llama el imaginario. Rabanal escribe su deseo de escribir en el momento de pasaje no unidireccional de la intimidad del scribens a la publicidad del auctor, y lo fecha en 1975, leyendo a Barthes. En aquel presente iniciático, cuando el escritor a punto de ser autor se desvela "con los ojos abiertos soñando con mi libro que saldrá este año", sintetiza la forma novelesca como serie de fragmentos protagonizados por un narrador titubeante, de un modo que vale para El apartado como para La vida escrita, solo que acá ese narrador se quita la máscara y descubre al fantasma:

Lo escribo para no olvidarlo: la novela no tiene por qué ser una organización clásica. Puede moverse en un terreno de fragmentos altamente significativos, como si se tratara de una serie de narraciones independientes en cada una de las cuales figura un protagonista que, en muchos casos, es solo el espectador de lo que ocurre y en algunos otros un mero narrador (vacilante) de los sucesos que se leen. No sé si será capaz de ponerlo a prueba (18).

Asumido en la incertidumbre, el desafío ético-poético se acerca a "lo deseable" según "El imaginario" de R.B. por R.B.: "no un texto de vanidad, ni un texto de lucidez, sino un texto de comillas inciertas, de paréntesis flotantes". La posición oscilante del narrador "depende también del lector, quien produce el escalonamiento de las lecturas" (1978: 116; itálicas en original).

También el autor como lector de sí mismo, en la autodestinación señalada por Genette, propone su escalonamiento. A punto de dejar de ser inédito, en septiembre de 1975 (y ochenta páginas después del autodesafío novelístico) se pregunta "qué significado serio puede tener el hecho de escribir novelas": "El apartado, ¿qué es para mí? El primer intento completo (básicamente lúdico) de componer una fantasía propia y hacerla pública" (Rabanal 2014: 103). La circulación del libro es otra instancia de desdoblamiento productivo, no solo para el reconocimiento del auctor y el relieve social 
del scriptor, sino para la autodestinación del scribens, el conocimiento del yo que vive en la práctica de escribir y persigue el estilo hundido en su mitología. Reconocimiento y autoconocimiento se conjugan en enero de 1977, cuando recibe como "regalo inesperado" una reseña internacional de El apartado, que señala a Kafka y a Beckett "como mis claros precedentes. No aparecen influencias argentinas notables. Creo que estoy plenamente de acuerdo" (160-161). Editando en 2014 lo anotado desde cuarenta años atrás, el novelista verifica que las primeras públicas lecturas de mí coinciden con las íntimas y originarias lecturas mías. Pero el reconocimiento no zanja la vacilación. Como prueban la estructura heterocrónica del libro y la extensa obra novelística de Rabanal, el escritor trabaja en el anacronismo y el desconocimiento, obedeciendo fuerzas ciegas para formular el imaginario, componer una fantasía y publicarla.

Novela que edita variaciones del espacio autobiográfico de quien durante cuatro décadas ha intentado ser novelista, $L a$ vida escrita sería otra tentativa lúdica de ese afán, complejizada por la utopía de narrar la historia de una primera persona que evoca al que ha sido y solo existe en el presente de escritura. La singularidad del estilo como lenguaje hundido en la mitología autoral trama un libro extraño, que reditúa interferencias entre géneros y discursos jugando con la imposibilidad de semejanza. Mejor que el relato de una vida cronológicamente pautado sobre una identidad imprecisa entre lo literario y lo extra literario, el imaginario del escritor diseña el espacio discontinuo de lo autobiográfico novelesco: casi una novela hecha de fragmentos editados en presente por alguien que, sin saber a qué fuerza obedece, vive escribiendo, asediando el desconocimiento del sujeto cuando asume un yo multiplicado por el lenguaje. Como en el imaginario de Barthes o en la tropología de De Man, el sujeto se desfigura en la escritura, aparece al desaparecer cada vez que dice yo. La variación pronominal señala el vacío de la máscara del autor borrado tras su narrador vacilante y su personaje novelesco, como apunta una nota de 1979, ubicada hacia el final de la trama editada: “¿A dónde se encamina mi personaje? Nadie lo sabe, no lo sabe él ni lo sé yo" (Rabanal 2014: 195). La vida escrita sería la novela utópica de un atrapante fracaso en la resolución de esa intriga.

Intensamente explorado en el devenir literario argentino (Sarmiento, Mansilla, Wilde, Macedonio, Borges, Saer, Aira), el borde textual entre autobiografía y ficción resulta un nudo pródigo para escritores como Piglia y Rabanal, que hacia mediados de la década de 1970 proyectan sus primeras novelas leyendo a Barthes y que, al editar sus diarios del pasado en la década de 2010, expanden el espesor ficcional y crítico de lo autobiográfico. Accionada en una especie de novela que fragmenta la continuidad tensando la intriga sobre el fantasma escrito en primera persona, en paralelo a Piglia pero reticente a la canonización académica, la contemporaneidad de Rabanal queda atravesada por "una falta cometida respecto de la conveniencia de los tiempos": al descronologizar la vida escrita, el anacronismo se vuelve fecundo frente al pasado insuficiente, que obstaculiza la comprensión de sí mismo (Didi-Huberman 2008: 42-43, 61 ; itálicas en original). Versátil en su vacilación, el narrador de Rabanal se desplaza entre los pasados y el presente al que está condenada la escritura (como el yo al imaginario). Paradójicamente dinámica por la subjetividad del lenguaje, esa peripecia hace presentes los comienzos: abre al infinito la búsqueda de la (primera) novela. 


\section{BIBLIOGRAPHY}

Agamben Giorgio, “¿Qué es lo contemporáneo?”, Otra parte. Revista de letras y artes ํํ20, otoño 2010, Buenos Aires, p. 78-90.

Arfuch Leonor, El espacio biográfico. Dilemas de la subjetividad contemporánea, Buenos Aires, FCE, 2002.

Barthes Roland (1972), Crítica y verdad, Buenos Aires, Siglo XXI.

--- (1978), Roland Barthes por Roland Barthes, Barcelona, Kairos.

--- (2005), La preparación de la novela. Notas de cursos y seminarios en el Collège de France, 1978-1979 y 1979-1980, Buenos Aires, Siglo XXI.

Benveniste Émile, Problemas de lingüística general, México, Siglo XXI, 1971.

Catelli Nora (1991), El espacio autobiográfico, Barcelona, Lumen.

--- (2007), En la era de la intimidad seguido de El espacio autobiográfico, Rosario, Beatriz Viterbo.

De Man Paul, “La autobiografía como desfiguración”, Loureiro Ángel (comp.), La autobiografía y sus problemas teóricos, Suplementos Anthropos nº 29, 1991, Barcelona, p. 113-118.

Didi-Huberman Georges, Ante el tiempo. Historia del arte y anacronismo de las imágenes, Buenos Aires, Adriana Hidalgo, 2008.

Domínguez Nora y Adriana Rodríguez Pérsico, "La pasión del modelo. Autobiografía de Victoria Ocampo", Lecturas críticas. Revista de investigación y teoría literarias año II, nº 2, marzo 1984, Buenos Aires, p. 22-34.

Dosse François, El arte de la biografía. Entre historia y ficción, México, Universidad Iberoamericana, 2007.

Genette Gerard, Umbrales, México, Siglo XXI, 2001.

Lejeune Philippe, Le pacte autobiographique, París, Editions du Seuil, 1975.

Molloy Sylvia, Acto de presencia. La escritura autobiográfica en Hispanoamérica, México, FCE, 1996.

Piglia Ricardo (sel. y pról.) (1968), Yo, Buenos Aires, Tiempo Contemporáneo.

--- (1993), Crítica y ficción, Buenos Aires, Siglo Veinte-UNL.

--- (2015), Los diarios de Emilio Renzi. Años de formación, Barcelona, Anagrama.

--- (2017), Los diarios de Emilio Renzi. Un día en la vida, Barcelona, Anagrama.

Premat Julio, “El autor. Orientación teórica y bibliográfica”, Premat Julio (ed.), Figures d'auteur. Figuras de autor, Cahiers de LI.RI.CO. Littératures contemporaines du Río de la Plata nº 1, 2006, SaintDenis, Université de Paris 8 Vincennes, p. 311-317.

Rabanal Rodolfo (1999), Los peligros de la dicha, Buenos Aires, Adriana Hidalgo.

--- (2014), La vida escrita, Buenos Aires, Seix Barral. 


\section{ABSTRACTS}

When the self that is taken as an object of writing includes its multiple alienation, it undoes the equivalence between author-narrator-character ruled by Lejeune in 1975. That year, Roland Barthes par Roland Barthes deconstructs the similarity by activating the writing of the self as another, in a pronominal sounding that mobilizes the imaginary as an effect of ignorance. This fictional and critical thickness of the autobiographical stuff is explored by Argentine writers like Ricardo Piglia and Rodolfo Rabanal: in the second decade of the XXI, with different strategies, they edit their personal diaries of the beginnings in the 70s, when they projected novel reading Barthes.

Cuando el yo que se toma como objeto de escritura incluye su ajenidad múltiple, deshace la equivalencia entre autor-narrador-personaje pautada por Lejeune en 1975. Ese año, Roland Barthes par Roland Barthes deconstruye la semejanza al accionar la escritura del sí mismo como otro, en un sondeo pronominal que moviliza el imaginario como efecto del desconocimiento. Este espesor ficcional y crítico de lo autobiográfico es explorado por escritores argentinos como Ricardo Piglia y Rodolfo Rabanal: en la segunda década del XXI editan con distintas estrategias sus diarios personales de los comienzos en los 70, cuando proyectaron novela leyendo a Barthes.

Quand le moi qui se prend comme objet d'écriture inclut son étrangeté multiple, il annule l'équivalence entre auteur-narrateur-personnage posée par Lejeune en 1975. Cette année-là, Roland Barthes par Roland Barthes déconstruit la similitude en activant l'écriture de soi-même comme un autre, dans une enquête pronominale qui mobilise l'imaginaire en tant qu'effet de méconnaissance. Cette épaisseur fictive et critique de l'autobiographique est explorée par des écrivains argentins tels que Ricardo Piglia et Rodolfo Rabanal: dans la deuxième décennie du XXIème siècle, ils éditent avec des stratégies différentes leurs journaux personnels des débuts dans les années 70, lorsqu'ils projetèrent de se tourner vers le roman en lisant Barthes.

\section{INDEX}

Keywords: anachronism, autobiographical space, writer readings, notation, novel

Palabras claves: anacronismo, espacio autobiográfico, lecturas de escritor, notación, novela

Mots-clés: anachronisme, espace autobiographique, lectures d'écrivain, notation, roman

\section{AUTHOR}

\section{JUAN PABLO LUPPI}

Consejo Nacional de Investigaciones Científicas y Técnicas, Argentina Instituto de Literatura Hispanoamericana, FFyL, UBA Departamento de Letras, FFyL, UBA

pabloluppi@hotmail.com 